\title{
Duloxetine treatment for relapse prevention in adults with generalized anxiety disorder: A double-blind placebo-controlled trial
}

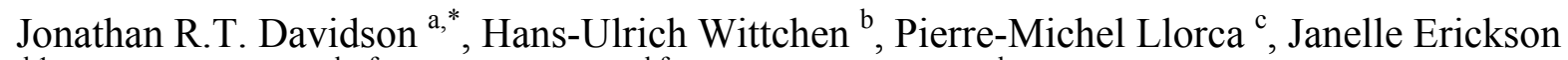
${ }^{\mathrm{d}, 1}$, Michael Detke ${ }^{\mathrm{d}, \mathrm{e}, \mathrm{f}}$, Susan G. Ball ${ }^{\mathrm{d}, \mathrm{f}}$, James M. Russell ${ }^{\mathrm{d}}$

\author{
a Duke University Medical School, Durham, NC, USA \\ b Institute of Clinical Psychology and Psychotherapy, Dresden, Germany \\ c Centre Hospitalier Universitaire, Clermont-Ferrand, France \\ d Lilly Research Laboratories, Indianapolis, IN, USA \\ e McLean Hospital/Harvard Medical School, Boston, MA, USA \\ f Indiana University School of Medicine, Indianapolis, IN, USA
}

\begin{abstract}
The objective was to examine duloxetine $60-120 \mathrm{mg} /$ day treatment for relapse prevention in adults with generalized anxiety disorder $(\mathrm{GAD})$. Adult patients $(\mathrm{N}=887$; mean age $=43.3$ years; $61.0 \%$ female) with DSM-IV-TR-defined GAD diagnosis were treated with duloxetine for 26 weeks. Patients who completed open-label phase and were treatment responders ( $\geq 50 \%$ reduction in Hamilton Anxiety Rating Scale total score to $\leq 11$ and "much"/"very much improved" ratings for the last 2 visits of openlabel phase) were randomly assigned to receive duloxetine or placebo for a 26 -week double-blind continuation phase. Relapse was defined as $\geq 2$-point increase in illness severity ratings or by discontinuation due to lack of efficacy. During the double-blind phase, placebo-treated patients $(\mathrm{N}=201)$ relapsed more frequently $(41.8 \%)$ than duloxetine-treated patients $(13.7 \%, \mathrm{~N}=204, \mathrm{P} \leq 0.001)$ and worsened on each outcome measure ( $\mathrm{P} \leq 0.001$, all comparisons). Duloxetine $60-120 \mathrm{mg} / \mathrm{day}$ treatment was efficacious and reduced risk of relapse in patients with GAD.
\end{abstract}

Keywords: Generalized anxiety disorder; Duloxetine; Relapse prevention; Treatment; Antidepressant; Serotonin and norepinephrine reuptake inhibitor

\section{Introduction}

Generalized anxiety disorder (GAD) is recognized as a chronic anxiety disorder with a persistent, deleterious course and substantial social impairment, as observed within community and epidemiological studies (Wittchen and Hoyer, 2001; Wittchen and Jacobi, 2005). Reflecting the persistence of GAD, the DSM-IV-TR diagnostic criteria for this disorder require excessive worry or anxiety that is difficult to control for at least 6 months (APA, 2000). Patients must also experience at least 3 of the following symptoms: restlessness, fatigue, difficulty concentrating, irritability, muscle tension, or sleep disturbance, for more days than not during this 6-month time frame. After the onset of GAD, the course may fluctuate in severity of symptoms, but impairment associated with GAD tends to persist, and spontaneous remission is rare (Yonkers et al., 1996). For example, in a naturalistic longitudinal study of anxiety patients (Harvard/Brown Anxiety Research Program), at the end of 12 years, the probability of recovery from an index episode of GAD was $58 \%$ and the probability of experiencing a recurrent episode for patients who had recovered was $45 \%$ (Bruce et al., 2005). 
In the context of persistence, long-term utility and tolerability must be considered when developing a treatment plan for GAD. Previously, benzodiazepines were the primary pharmacological intervention; however, concerns about abuse liability, development of tolerance, and loss of efficacy have reduced the usefulness of benzodiazepines for long-term illness management of chronic anxiety (Mahe and Balogh, 2000). In addition, the understanding that the neurobiology of GAD involves multiple neurotransmitter systems has shifted treatment recommendations to the use of selective serotonin reuptake inhibitors (SSRIs) and serotonergic noradrenergic reuptake inhibitors (SNRIs) as first-line pharmacological interventions (Goodman, 2004).

Long-term treatment efficacy has been studied using double-blind, placebo-controlled trials, in which the therapy period has been extended to $\geq 12$ weeks. Gelenberg et al. (2000) examined the efficacy of venlafaxine XR compared with placebo for a 6-month treatment phase and found venlafaxine treatment was associated with significantly greater improvement in anxiety at study end point compared with placebo treatment. Due to concerns about study attrition and the use of placebo long-term, an alternative study design that has been used for long-term efficacy is the randomized withdrawal design that is also termed relapse prevention. In this design, patients are initially treated using open-label active treatment; responders are then entered into a double-blind continuation phase where they are randomly assigned to maintain active treatment or switch to placebo and then followed for relapse. The randomized withdrawal design has been used for controlled studies of paroxetine and escitalopram (SSRIs) and venlafaxine (SNRI). Overall, patients treated with the SSRI treatments showed less risk of relapse compared with placebo for treatment periods of 24 to 76 weeks, but this finding was not observed with venlafaxine (Allgulander et al., 2006; Stocchi et al., 2003; Hackett et al., 2000).

Duloxetine, an SNRI, was recently approved for the treatment of GAD in adults based on 3 independent, placebo-controlled, acute-therapy (9-10 weeks) trials (Rynn et al., 2008; Koponen et al., 2007; Hartford et al., 2007). The objective of the present study was to examine the long-term efficacy of duloxetine $60 \mathrm{mg}$ to $120 \mathrm{mg}$ once daily for the prevention of relapse in patients with GAD who responded therapeutically to an initial 6-month course of duloxetine treatment.

\section{Experimental procedures}

\subsection{Study design}

The study design was a randomized relapse prevention study with a 26-week open-label, flexible-dose acute-therapy phase with duloxetine followed by a 26 -week double-blind, placebo-controlled continuation therapy phase; the study also had a screening and a 3-week taper/follow-up therapy phase. In the open-label phase, patients were started with duloxetine $30 \mathrm{mg} /$ day for 1 week that was then increased to $60 \mathrm{mg} /$ day. After 4 weeks of treatment, doses were managed flexibly based on the physician's judgment; however, if a patient's Clinical Global Impressions Improvement (CGI-I; Guy, 1976a) rating was minimal improvement, no change, or worse after 4 weeks, a $30-\mathrm{mg} /$ day dose increase was required up to a maximum of $120 \mathrm{mg} /$ day. Patients could decrease dose if tolerability concerns arose; the minimum allowable dose was $60 \mathrm{mg}$, and dosage was stabilized after 8 weeks of treatment. During the open-label phase, patients were assessed monthly at weeks 8 through 20 and then biweekly at weeks 22, 24, and 26. 
Patients who completed the open-label phase and met response criteria were eligible for the double-blind continuation phase. Responder status was required for the last 2 consecutive visits of the open-label trial and was defined as a $\geq 50 \%$ reduction in Hamilton Anxiety Rating Scale (HAMA; Hamilton, 1959) total score from baseline to a score $\leq 11$ and a CGI-I rating of "very much" or "much improved". Nonresponders were discontinued from the study.

Although the study design and protocol were blinded regarding the time of randomization (weeks 22 to 26), the actual double-blind assignment of treatment occurred at week 26 in a 1:1 ratio and was administered via an interactive voice recognition system. Patients who were randomly assigned to placebo underwent a 2-week taper of study medication, while those assigned to duloxetine were continued at the same dose as their open-label phase treatment. All doses were taken once daily, and to maintain the blind, all patients received 4 capsules throughout the double-blind phase. After randomization at week 26, visits occurred at weeks $28,32,36,40,44,48$, and 52 .

The study was implemented in accordance with the principles of Good Medical Practice and the Declaration of Helsinki (WMA, 2000). Each investigative site approved the protocols independently through external review boards, and all patients provided informed written consent. The blind regarding the onset of randomization to the double-blind phase was maintained by submission of a protocol supplement directly to the external review boards, independently of investigative sites.

\subsection{Patients}

Male and female patients aged $\geq 18$ years were recruited globally from outpatient psychiatric clinics and university settings (28 sites throughout Austria, France, Germany, Portugal, and the Netherlands and 22 sites in the United States). Patients had to meet the Diagnostic and Statistical Manual of Mental Disorders, IV edition, text-revision criteria for GAD (DSM-IVTR; APA, 2000), which were assessed via the Mini International Neuropsychiatric Interview for the DSM (MINI; Sheehan et al., 1998) and confirmed by study psychiatrist. Patients' illness had to be at least moderately severe as indicated by a Clinical Global Impressions Severity (CGI-S; Guy, 1976a) rating of $\geq 4$ (moderate), a Hospital Anxiety and Depression Scale (HADS; Zigmond and Snaith, 1983) anxiety subscale score $\geq 10$, and a Covi Anxiety Scale (CAS; Lipman and Covi, 1976) score $\geq 9$. To ensure predominance of anxiety symptoms, none of the 5 items on the Raskin Depression Rating scale (RDR; Raskin et al., 1969) could be scored N3, and the CAS score had to be greater than the RDR total.

Patients were not eligible to participate in the study if they met any of the following diagnoses: current or previous 6-month diagnosis of major depressive disorder, or substance abuse or dependence; a past year history of panic disorder, posttraumatic stress disorder, or an eating disorder; or a lifetime diagnosis of obsessive-compulsive disorder, bipolar affective disorder, psychosis, factitious disorder, or somatoform disorder. They were excluded if they were taking psychotropic medications within 7 days before baseline (14 days for benzodiazepines and 4 weeks for fluoxetine or a monoamine oxidase inhibitor), consuming excessive caffeine per investigator judgment, or had any medical condition that would contraindicate taking duloxetine. Women who were breastfeeding or pregnant were not allowed to participate, and women of childbearing potential were required to use reliable methods of birth control. Patients who had a prior treatment history with duloxetine or whose GAD had failed to respond to 2 adequate trials of pharmacological treatment per the treating physician were ineligible as well. 


\subsection{Outcome measures}

The primary efficacy measure was the time to relapse during the 26- week double-blind continuation therapy phase. Relapse was defined as an increase in the CGI-S rating of at least 2 points from randomization (end of open-label phase) to a score $\geq 4$ (moderate) while meeting criteria for GAD confirmed by the MINI or by discontinuation due to lack of efficacy.

The secondary efficacy measure was the HAMA total score, which was administered using the Structured Interview Guide for the HAMA version (SIGH-A; Shear et al., 2001). The HAMA is a clinician-rated instrument consisting of 14 items that are rated on a 0 ("not at all") to4 ("very severe/disabling") scale; higher total scores indicate greater distress and impairment. The SIGH-A version specifies instructions for administration and scoring based on frequency, severity, and impairment of symptoms and has been demonstrated to increase reliability (Shear et al., 2001). Study personnel involved in assessing patients were required to obtain sponsor approval, which was based on their demonstrating interviewing competence via mock interviews and scoring reliability via a videotaped interview. The intraclass correlation coefficient for the HAMA total score was 0.91 for the training tape and 0.87 for a recalibration tape during the study; both values indicate excellent interrater reliability.

Additional outcome measures included the HAMA psychic factor score (sum items 1-6, 14) and the HAMA somatic factor scores (sum of items 7-13). Patients completed the 14-item HADS, which consists of separate subscales ( 7 items each) for anxiety and depression; higher scores indicate greater symptom frequency or distress. Overall improvement was rated by clinicians using the CGI-I and by the patients using the Patient Global Impressions of Improvement (PGI-I; Guy, 1976b). Ratings for these scales range from 1 to 7, in which lower scores indicate greater improvement. CGI-I and CGI-S ratings were required to be completed by a physician who had at least 1 year experience in the treatment of patients with anxiety disorders.

Role functioning was assessed by the Sheehan Disability Scale (SDS; Sheehan, 1983), in which patients rated their degree of impairment using a 10-point scale from 0 ("none") to 10 ("extremely disabling") for 3 life domains: work/school, social life, and family/ home responsibilities. The global functioning impairment score is the sum of the 3 items, and global scores N5 have been shown to indicate impairment associated with psychiatric illness (Leon et al., 1997). Patients' satisfaction with their lives and perceived health were measured by the Quality of Life Enjoyment and Satisfaction Questionnaire-Short Form (Q-LES-Q-SF; Endicott et al., 1993) and the European Quality of Life: 5 Dimensions Visual Analogue Scale (EQ-5D VAS; EuroQol, 1990).

Tolerability of study medication was assessed by spontaneously reported adverse events (AEs) and reasons for study discontinuation. At each visit, clinicians also completed the Beck Scale for Suicidal Ideation (BSSI; Beck et al., 1979), which has an initial screening question; positive responses to the screening are followed by detailed assessment of a patient's behaviors, attitudes, and plans to commit suicide. Although any positive score on this scale has been associated with increased risk for suicidal behaviors, a score of $\geq 6$ has been used to denote at least moderate ideation and significant risk for suicidal behaviors (Sokero et al., 2003). Vital signs were also collected at each visit. 
The study sample size was targeted for 760 patients to obtain $90 \%$ power based on assumptions of $15 \%$ relapse rate in duloxetine, $30 \%$ relapse rate for placebo, a $52 \%$ discontinuation rate during the open-label phase, and a 2 -sided log-rank test with á $=0.05$ significance level. Values were defined for baseline (last nonmissing value for visits 1 and 2); open-label end point (last nonmissing value for weeks 1-26); double-blind baseline (last nonmissing value for weeks 1-26); and study end point (last observed nonmissing value for weeks 1-52). Treatment response was defined as a $\geq 50 \%$ reduction in Hamilton Anxiety Rating Scale total score from baseline to a score $\leq 11$ and a CGI-I rating of "very much" or "much improved". Remission was defined as a HAMA total score at end point $\leq 7$.

The primary efficacy analysis was time to relapse during the double-blind continuation phase. Patients who did not relapse were censored at study end point. Survival curves were constructed using the Kaplan-Meier product limit method and compared using a stratified log-rank test controlling for investigator. Relapse rates between groups were compared using a Cochran-Mantel-Haenzel test controlling for investigator and were based on the number of patients with a baseline and at least one nonmissing post-baseline observation.

For the open-label phase, efficacy analyses were based on all patients enrolled into the duloxetine treatment. Mean changes between baseline to open-label study end point were analyzed using t-tests to determine if they were significantly different from zero. For the double-blind phase, efficacy analyses were based on the intent-to-treat sample, which consisted of all patients with a double-blind randomization observation and a postrandomization observation. An analysis-of-covariance (ANCOVA) model was used to compare treatment group differences from double-blind baseline to study end point on continuous variables with treatment and investigator as main effects, and the double-blind baseline score as the covariate. For the CGI and PGI improvement ratings, study end-point values were compared using an analysis of variance (ANOVA) with treatment and investigator as main effects. To examine changes across time, a repeated measures maximum likelihood-based mixed-effects model was used for the HAMA total score with fixed effects of treatment, investigator, visit, and treatment-by-visit interactions and covariates of the double-blind baseline score and baseline-by-visit interaction. All mean changes, unless otherwise noted, refer to least-squares means, which are adjusted for the model. Relapse and remission (HAMA total score $\leq 7$ at end point) rates between treatment groups were compared using a Cochran-Mantel-Haenzel test controlling for investigator. For categorical safety variables frequencies between groups in the double-blind phase were compared using Fisher's exact test.

\section{Results}

\subsection{Patient characteristics and disposition}

The study was conducted between January 2005 and March 2007. A total of 1132 patients were screened for the study, and 887 met inclusion/exclusion criteria and were enrolled into the open-label phase. As anticipated, $51.5 \%$ of the study participants discontinued during the 6-month open-label phase (Fig. 1). The most frequent reasons for study discontinuation were adverse events (13.6\%), subject decision $(12.0 \%)$, or failure to meet responder criteria by end of the open-label phase (9.7\%). Dose escalation did not occur for 148 patients $(20.7 \%)$, whereas the dose for 299 patients $(41.8 \%$ ) was increased to $90 \mathrm{mg}$ /day and for 268 patients 
$(37.5 \%)$, to $120 \mathrm{mg} /$ day. The mean duration of study drug exposure for the open-label phase was 136.0 days $(\mathrm{SD}=70.1)$.

At the double-blind baseline, there were no significant differences between patients randomly assigned to duloxetine $(n=216)$ or placebo $(n=213)$ in their demographics or illness characteristics (Table 1). The majority of the sample was female and Caucasian. The mean duration of study drug exposure during the double-blind phase was 156.1 days $(\mathrm{SD}=55.7)$ for duloxetinetreated patients and 125.3 days $(\mathrm{SD}=67.2)$ for placebo-treated patients $(\mathrm{P} \leq 0.001)$. Patients who were assigned to placebo were significantly more likely to withdraw from the continuation phase due to lack of efficacy than patients treated with duloxetine $(31.0 \% \mathrm{vs}$ $9.7 \%, \mathrm{P} \leq 0.001)$.

\subsection{Open-label treatment efficacy}

For patients who completed the open-label phase, $78.8 \%(n=533)$ of patients met the responder criteria and were eligible for randomization to the double-blind phase. Duloxetine treatment was associated with significant improvement on all secondary efficacy and patient functioning measures. Patients experienced improvements in their illness severity, as indicated by a mean decrease from baseline in HAMA total score of -14.9 ( $\mathrm{SD}=10.1$, $\mathrm{P} \leq 0.001$, within subject) and in their role functioning. The mean SDS global functioning score at the open-label end point indicated minimal impairment (Table 2). In the intent-totreat sample, the remission rate at open-label end point was $44.3 \%(n=858)$.

\subsection{Double-blind continuation phase treatment efficacy}

Significantly more placebo-treated patients $(n=84, N=201,41.8 \%)$ met relapse criteria compared with duloxetine-treated patients $(n=28, N=204,13.7 \% ; P \leq 0.001)$. Among patients who did relapse, duloxetine-treated patients had a longer time to relapse compared with patients who were switched to placebo (Fig. 2, log-rank test, $\mathrm{P} \leq 0.001$ ). At week 28, which was the end of the medication taper for the placebo group, the number of patients who discontinued from the study was the same within the placebo and the duloxetine group $(n=4)$.

Patients who were continued with duloxetine treatment maintained the improvements that were demonstrated during the open-label phase. Patients who were switched to placebo significantly worsened on each of the secondary outcome measures, including the HAMA total score (Fig. 3), HAMA psychic factor score, HAMA somatic factor scores, and HADS anxiety subscale (all comparisons between duloxetine and placebo, $\mathrm{P} \leq 0.001$, Table 2 ). The remission rate for duloxetine-treated patients at end point was $68.1 \%(n=145)$, which was significantly greater than the remission rate for placebo-treated patients $(n=83,39.3 \%$, $\mathrm{P} \leq 0.001)$.

With regard to functional impairment, patients treated with placebo during the double-blind phase also had a worsening of their role functioning in all 3 SDS domains of work/school, social life, and family/home management compared with patients who continued with duloxetine ( $\mathrm{P} \leq 0.001$; Table 2$)$. By study end point, the mean SDS global functioning impairment score for the placebo group had significantly increased into the range indicating mild to moderate impairment $(\mathrm{P} \leq 0.001$; Table 2$)$. Patients in the placebo group were rated as overall less improved by both the CGI-I and PGI-I mean end-point scores compared with patients in the duloxetine group ( $\mathrm{P} \leq 0.001$, both comparisons). The switch to placebo was also associated with decreased life satisfaction and poorer perceived health, as measured by the 
mean changes in Q-LES-Q-SF and EQ-5D VAS scores ( $\mathrm{P} \leq 0.001$, all comparisons; Table 2) compared with patients who continued with duloxetine.

\subsection{Tolerability}

\subsubsection{Open-label treatment phase}

During the open-label phase, 15 treatment-emergent AEs occurred at a frequency of $\geq 5 \%$ : nausea $(28.3 \%)$, headache $(18.7 \%)$, dry mouth $(14.3 \%)$, diarrhea $(14.2 \%)$, dizziness $(13.4 \%)$, constipation $(12.5 \%)$, fatigue $(11.5 \%)$, hyperhidrosis $(10.0 \%)$, insomnia $(9.8 \%)$, somnolence $(8.2 \%)$, decreased appetite $(6.1 \%)$, upper respiratory tract infection $(5.5 \%)$, decreased libido (5.4\%), vomiting (5.4\%), and nasopharyngitis (5.0\%). Eighteen patients $(2.0 \%)$ had a positive response to the initial screening questions of the BSSI during the open-label phase. At end point, these patients had a mean BSSI score of 5.7 (values observed ranged $0-19, \mathrm{SD}=6.1$ ), which did not differ significantly from their baseline mean value of 5.4 (values observed ranged $0-26 ; \mathrm{SD}=6.6 ; \mathrm{P}=0.84$ ). Mean change from baseline to open-label end point was 2.2 bpm $(\mathrm{SD}=10.3)$ for pulse rate $(\mathrm{Pb} 0.001$ within subject $), 0.68 \mathrm{~mm} / \mathrm{Hg}(\mathrm{SD}=12.2)$ for systolic $\mathrm{BP}(\mathrm{P}=0.104)$, and $1.1 \mathrm{~mm} / \mathrm{Hg}(\mathrm{SD}=8.7)$ for diastolic $\mathrm{BP}(\mathrm{Pb} 0.001)$.

Most AEs were rated as mild to moderate in severity. Discontinuation from the study due to AEs occurred for $13.6 \%$ of patients $(n=121)$, with nausea being the most frequent $A E(n=11$, $1.2 \%$ ). The remaining AEs that led to discontinuation were each cited at a frequency of b1.0\%. Eleven patients experienced serious AEs (SAEs) that included acute alcoholic intoxication, alcohol dependency, anxiety, arrhythmia, cellulitis, cerebral hemorrhage (resulted in patient death), depression, diverticulitis, mania, nephrolithiasis, attempted suicide ( 2 patients), suicide (resulted in fatality), stress, and syncope. For the patient who died by cerebral hemorrhage, vital signs were normal at the visit prior to death; duloxetine dose was $60 \mathrm{mg} /$ day, and concomitant medications included acetylsalicylic acid and ibuprofen. For the patient who died by suicide, the SSI score was 0 at the visit before death; duloxetine dose was $60 \mathrm{mg} /$ day, and concomitant medications were lercanidipine hydrochloride, elidiur, allopurinol, esomeprazole, and ferrous aminopropane dicarboxylate.

\subsubsection{Double-blind continuation phase}

During the double-blind continuation phase, placebo-treated patients experienced discontinuation-emergent AEs as the study medication was being withdrawn. Compared with patients in the duloxetine group, dizziness was the only AE to occur significantly more often in the placebo group ( $9.9 \%$ vs $3.7 \%, \mathrm{P} \leq 0.05)$. No significant increases in pulse rate, diastolic $\mathrm{BP}$, or systolic BP were observed during the double-blind phase in duloxetine-treated patients compared with placebo-treated patients.

Most AE symptoms were rated mild to moderate in severity. Discontinuation from the study due to AEs occurred for 4 patients $(1.9 \%)$ in the duloxetine group (acute bronchitis, 1 ; pregnancy, 2; epileptic seizure, 1) and for 2 patients in the placebo group (dizziness, 1; weight gain, 1) $(\mathrm{P}=0.685)$. Combining the open-label and double-blind phases, the overall rate of discontinuation due to AE for duloxetine-treated patients was 125/887 (14.1\%). During the double-blind phase, the SAEs within the duloxetine group were bronchitis, diarrhea, and worsening of GAD (1 patient each); within the placebo group, 1 patient had a fall with a ruptured tendon. 


\section{Discussion}

The results of this study demonstrate long-term efficacy of duloxetine in the treatment of GAD in adults. For patients who initially responded to duloxetine treatment, continuation with duloxetine $60 \mathrm{mg}$ to $120 \mathrm{mg}$ once daily significantly reduced the risk of subsequent relapse, compared with placebo, during the study period of 6 months. When duloxetinetreated patients with GAD were switched to placebo, their symptoms significantly worsened across illness severity and functional outcome measures, and these patients had 3 times the rate of relapse compared with patients who were continued on duloxetine $(41.8 \%$ vs. $13.7 \%$, respectively). Although placebo-treated patients underwent medication taper, the rate of relapse was not associated with the discontinuation period, and therefore likely reflects a return of an active disease state.

The magnitude and risk of relapse following withdrawal of duloxetine were similar to rates observed in other relapse prevention studies. For patients who responded to escitalopram treatment after 12 weeks and were switched to placebo, the rate of relapse (defined as HAMA total score $\geq 15$ ) was $56 \%$ compared with a rate of $19 \%$ for those who continued on escitalopram for another 24 to 76 weeks (Allgulander et al., 2006). Similarly, for patients who responded to an 8-week trial of paroxetine, double-blind randomization to either placebo or continued paroxetine for another 24 weeks resulted in relapse rates (defined as an increase in CGI-S ratings of $\geq 2$ from randomization) of $39.9 \%$ and $10.9 \%$, respectively (Stocchi et al., 2003). On the other hand, another similarly designed study (8-week open-label/24-week double-blind) of venlafaxine extended-release did not find significant differences in relapse rates between those who were switched to placebo and those who continued active treatment (16\% vs $12 \%$, respectively) (Hackett et al., 2000). Nonetheless, notwithstanding the differences in design, duration, and definitions of response and relapse, the preponderance of evidence supports the conclusion that these pharmacological interventions continue to be efficacious during long-term treatment.

Without a placebo control, the frequency of treatment-emergent AEs in the open-label phase cannot be definitively associated with duloxetine treatment. The suicide behaviors that occurred during the open-label phase of this trial were unexpected and have not been observed in the acute trials for GAD; a meta-analysis of controlled trials with duloxetine for major depressive disorder did not show increased risk for suicide behaviors and ideation (Acharya et al., 2007). On the other hand, suicide ideation and behaviors have been associated with generalized anxiety disorder in epidemiological and longitudinal studies (Sareen et al., 2005; Boden et al., 2007). Overall, the number and type of the most frequent treatmentemergent AEs were comparable with those observed in the placebo-controlled double-blind studies (i.e, approximately 12 treatment-emergent AEs, with nausea being the most frequent). A pooled analysis of the 3 acute trials showed a study discontinuation rate due to treatmentemergent AEs of $15.6 \%$ (Allgulander et al., 2007), which was slightly higher than the $14.1 \%$ rate observed within this 52 -week study. Similarly, the mean changes in pulse rate and systolic BP were consistent with the cardiovascular profile of duloxetine (Thase et al., 2005).

One strength of the study design was the 6-month duration for the open-label phase, which allowed stabilization of response to duloxetine treatment; therefore, the recurrence of symptoms in the continuation phase is likely to reflect a recurrence of the illness rather than symptom fluctuation. However, the long duration of the study also created the logistical challenge of patient retention in the study. As anticipated, approximately half of the enrolled patients discontinued in the initial 6 months, with patient decision being one of the leading 
reasons for discontinuation. This rate of study completion in a sample of patients with GAD parallels rates of adherence to antidepressant treatment observed within naturalistic and claimbased studies (McManus et al., 2004; Stein et al., 2006). Although patient adherence is related to multiple factors, patient's knowledge and perception of benefit are a key dimension (Wagner et al., 1996). Recognition that discontinuation resulted not only in a return of symptom severity, but diminished quality of life, therefore, may be informative to assist patients in adherence. Another strength of the study design was the use of stringent criteria for response and relapse to assure that the changes that occurred during the course of the study were clinically meaningful. In addition, patients were unaware of the exact timing of the potential withdrawal of medication, which may have helped to reduce patient's and clinician's expectancies as to the timing and likelihood of relapse.

The results of the present study should also be evaluated in the context of a few limitations. As noted, attrition occurred throughout the study, which may limit the generalizability of the findings. Secondly, the patients were selected for having primary GAD without significant comorbidity. Because GAD is frequently comorbid with both anxiety and affective disorders, the findings may not generalize to the clinical patient who has substantial comorbidity among the different disorders.

In summary, duloxetine 60 to $120 \mathrm{mg}$ once daily was efficacious in attaining and continuing remission during the course of a year for patients with GAD. A frequent question for both patients and physicians in developing a treatment plan is what should be the optimal duration for continued treatment after a therapeutic response has been obtained. For many patients, the remission of symptoms may equate to the absence of a disease state and hence a propensity to discontinue treatment. Whereas the present study cannot describe the actual underlying state of pathology, the results suggest that additional 6-month treatment provided continued protective benefit. Therefore, physicians and patients should consider a chronic illness model for GAD as a reference point in developing their treatment plans (Keller, 2002). 


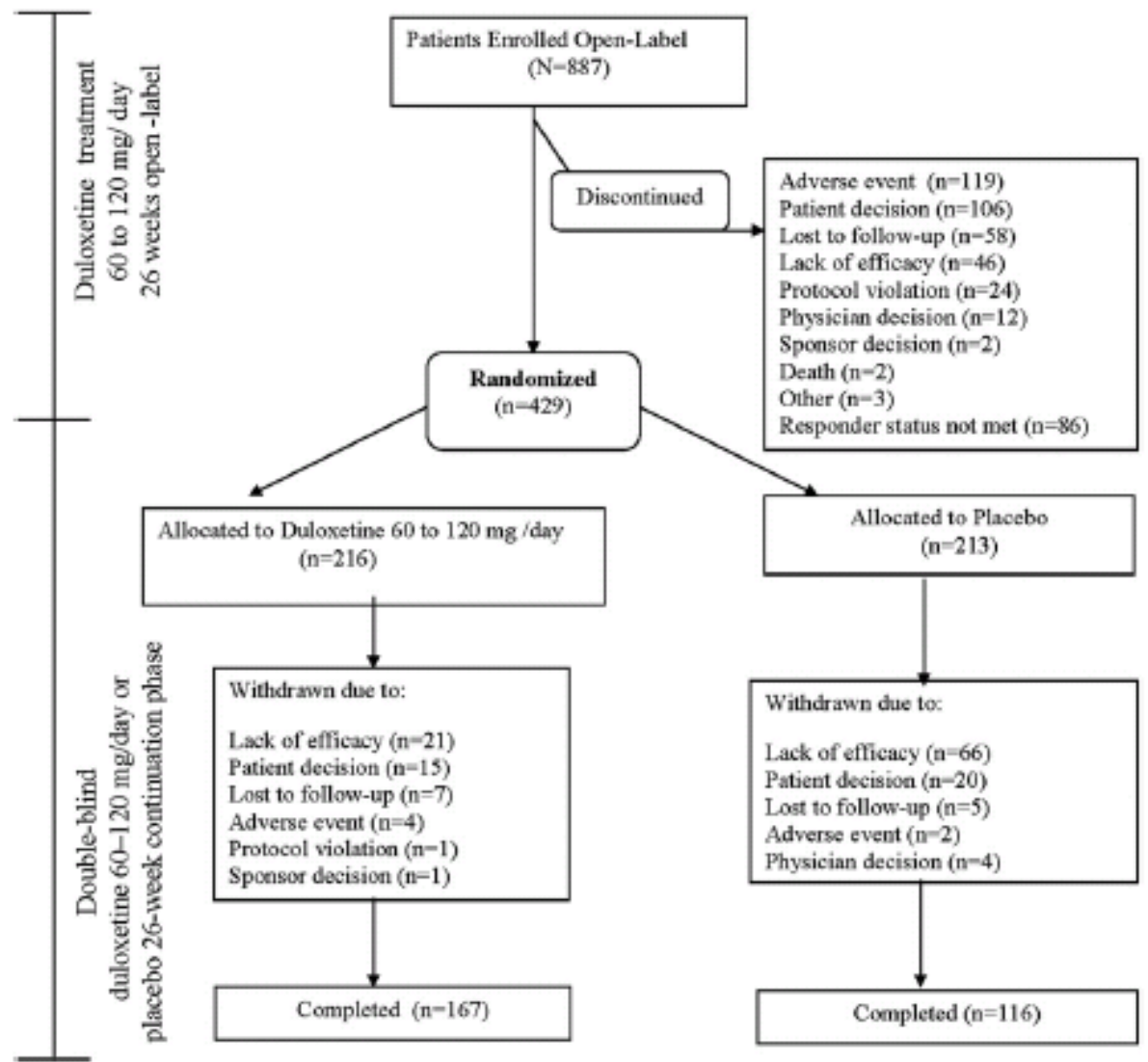

Figure 1 Patientenrolment and disposition during the 26-wedk open-label phase and the 26-week double-blind continuation therapy phase.

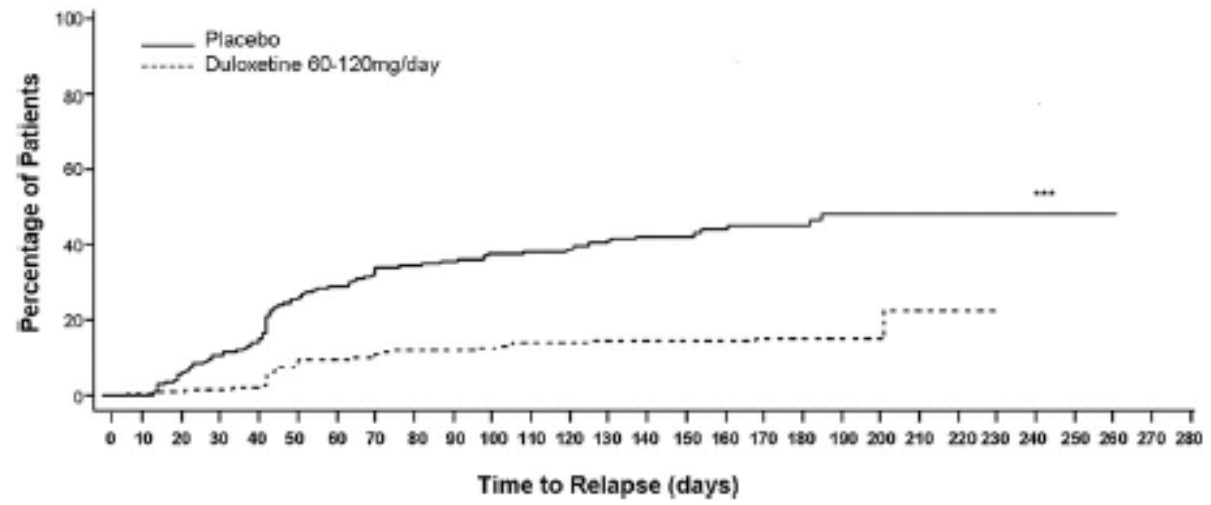

Figure 2 Time to relapse during the 26-week double-blind continuation phase for patients randomly assigned to duloxetine 60 to $120 \mathrm{mg}$ or placebo treatment. ${ }^{-\infty}$ P<0.001 (log-rank test). 


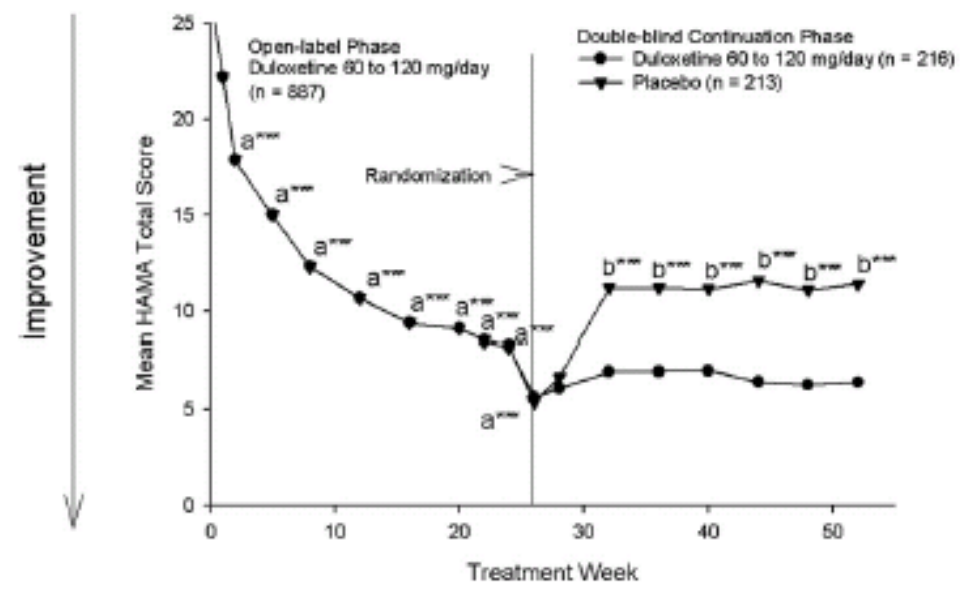

Figure 3 Mean Hamilton Anxiety Rating Scale total score during the 26-week open-label and 26-week double-blind continuation phases. a** $P \leq 0.001$, within subject; $b^{-*} P \leq 0.001$, placebo vs. duloxetine.

Table 1 Patient demographics and illness characteristics at start of the open-label phase and at randomization for double-blind continuation phase

\begin{tabular}{|c|c|c|c|}
\hline \multirow[t]{2}{*}{ Variable } & \multirow{2}{*}{$\frac{\text { 26-Week open-label phase }}{\text { Duloxetine } 60-120 \mathrm{mg} / \text { day }(\mathrm{N}=887)}$} & \multicolumn{2}{|c|}{ 26-Week double-blind continuation phase } \\
\hline & & Duloxetine $60-120 \mathrm{mg} /$ day $(\mathrm{N}=216)$ & Place bo $(N=213)$ \\
\hline Age, years (SD) & $43.3(13.4)$ & $45.0(13.2)$ & $45.7(14.1)$ \\
\hline \multicolumn{4}{|l|}{ Sex, $n(\%)$} \\
\hline Female & $541(61.0)$ & $132(61.1)$ & $125(58.7)$ \\
\hline Male & $346(39.0)$ & $84(38.9)$ & $88(41.3)$ \\
\hline \multicolumn{4}{|l|}{ Racial origin, $n$ (\%) } \\
\hline African & $17(1.9)$ & $7(3.2)$ & $3(1.4)$ \\
\hline Caucasian & $754(85.0)$ & $185(85.7)$ & $191(89.7)$ \\
\hline Hispanic & $98(11.1)$ & $18(8.3)$ & $15(7.0)$ \\
\hline Asian & $18(2.0)$ & $6(2.8)$ & $4(1.9)$ \\
\hline Prior benzodiazepine use, $n(\%)$ & $204(23.0)$ & $47(21.8)$ & $49(23.0)$ \\
\hline
\end{tabular}

At the double-blind baseline, no significant differences were found between the treatment groups.

Key: SD, standard deviation.

Table 2 Mean changes on secondary efficacy and functional outcome measures from double-blind continuation baseline to study end point by treatment group (intent-to-treat anatysis)

\begin{tabular}{|c|c|c|c|c|}
\hline \multirow[t]{2}{*}{ Variable } & \multicolumn{2}{|c|}{$\begin{array}{l}\text { Double-blind continuation phase mean scores at } \\
\text { randomization }\end{array}$} & \multicolumn{2}{|c|}{$\begin{array}{l}\text { Double-blind continuation phase mean change from } \\
\text { randomization to end point (LOCF) }\end{array}$} \\
\hline & $\begin{array}{l}\text { Duloxetine } \\
60-120 \mathrm{mg}(n=213) \text { mean (SD) }\end{array}$ & $\begin{array}{l}\text { Placebo } \\
(n=211) \text { mean (SD) }\end{array}$ & $\begin{array}{l}\text { Duloxetine } \\
60-120 \mathrm{mg}(n=213) \text { mean (SE) }\end{array}$ & $\begin{array}{l}\text { Placebo } \\
(n=211) \text { mean }(S E)\end{array}$ \\
\hline HAMA total score & $5.4(2.9)$ & $5.6(3.1)$ & $1.6(0.6)$ & $7.5(0.6)^{\cdots *}$ \\
\hline HAMA psychic factor & $2.8(1.9)$ & $3.0(1.9)$ & $1.2(0.3)$ & $4.5(0.3)^{\cdots *}$ \\
\hline HAMA somatic factor & $2.6(1.9)$ & $2.6(2.0)$ & $0.3(0.3)$ & $3.0(0.3)^{\cdots}$ \\
\hline HADS anxiety subscale & $4.7(3.3)$ & $4.7(2.9)$ & $0.1(0.3)$ & $3.5(0.3)^{\cdots *}$ \\
\hline HADS depression subscale & $3.1(3.3)$ & $3.1(3.0)$ & $0.0(0.2)$ & $2.2(0.3)^{\cdots *}$ \\
\hline $\begin{array}{l}\text { SDS global functioning } \\
\text { impairment }\end{array}$ & $4.6(5.7)$ & $4.5(4.8)$ & $0.6(0.5)$ & $5.0(0.5)^{\cdots}$ \\
\hline SDS work/school & $1.4(1.8)$ & $1.4(1.7)$ & $0.1(0.2)$ & $1.7(0.2)^{\cdots *}$ \\
\hline SDS social tife & $1.5(2.0)$ & $1.5(1.8)$ & $0.2(0.2)$ & $1.7(0.2)^{\cdots *}$ \\
\hline $\begin{array}{l}\text { SDS famity life/home } \\
\text { responsibilities }\end{array}$ & $1.6(2.1)$ & $1.5(1.8)$ & $0.2(0.2)$ & $1.6(0.2)^{\cdots *}$ \\
\hline $\begin{array}{l}\text { Q-LES-Q-SF percent } \\
\text { maximum total score }\end{array}$ & $74.4(15.0)$ & $74.4(14.6)$ & $-0.3(1.2)$ & $-12.5(1.2)^{\ldots *}$ \\
\hline EQ-5D VAS & $80.2(14.8)$ & $80.4(13.7)$ & $1.3(1.3)$ & $-12.7(1.3)^{m *}$ \\
\hline
\end{tabular}

Least-squares means from ANCOVA model.

Key: SD, standard deviation; SE, standard error; HAMA, Hamilton Anxiety Rating Scale; HADS, Hospital Anxiety and Depression Scale; SDS, Sheehan Disability Scale; Q-LES-Q-SF, Quality of Life Enjoyment and Satisfaction Scale-Short Form; EQ-SD VAS, European Quality of Life. 5 Dimensions Visual Analogue Scale; LOCF, last observation carried forward.

$* \cdots p \leq 0.001$. 


\section{Role of the funding source}

This research was funded by Eli Lilly and Company and Boehringer Ingelhem GmbH. Funding support included personnel and materials involved in study design; collection, analysis and interpretation of data; and the writing of the report.

\section{Contributors}

Drs. Russell and Detke directed and executed the primary clinical trials. Dr. Davidson developed the study design, analytic approach, and interpretation of data. Drs. Wittchen and Llorca were clinical investigators at individual sites and also participated in data analyses and interpretation. Dr. Ball contributed to data analysis and interpretation as well as manuscript preparation. Statistical analyses were directed by Dr. Erickson. All authors participated in writing team meetings and contributed to the first draft. All authors have also read and approved the final manuscript version.

\section{Conflict of interest}

In the past 12 months, Dr. Davidson reports having received support as follows: speaking fees from Psychiatric Society of Virginia, Texas Society of Psychiatric Physicians; research support from International Psychopharmacology Algorithm Project, Janssen, Glaxo Smith Kline, Cephalon; stock holdings with Procter and Gamble; advisor to Actelion, Forest, Eli Lilly and Company, Roche Diagnostics, Jazz, Astra Zeneca, Wyeth, Sanofi-Aventis, Brain Cells, Epix, Transcept; royalties from MultiHealth Systems Inc, Guilford Publications, American Psychiatric Association; expert witness details available on request. Dr. HansUlrich Wittchen has been receiving support as follows: Speaker's fees from Eli Lilly and Company, Novartis, Pfizer, Lundbek, and Sanofi-Aventis; grant support from Pfizer, SanofiAventis and Novartis. Dr. Wittchen also serves as consultant to Pfizer, Sanofi-Aventis, Lundbek and Organon. Dr. Pierre-Michel Llorca is a consultant for Eli Lilly and Company, Janssen, Lundbeck, and Sanofi- Aventis. He has received honoraria from Bristol Myers Squibb, Eli Lilly and Company, Janssen, and Sanofi-Aventis. Drs. Detke, Ball, and Russell are employees and shareholders of Eli Lilly and Company. Dr. Erickson was previously an employee and shareholder of Eli Lilly and Company.

\section{Acknowledgements}

We thank the patients who participated in the study. We would like to acknowledge our appreciation to the following principal investigators and their clinical research staff: Dr. Voker Arolt, Dr. Borwin Bandelow, Dr. Bertrand Baranosvsky, Dr. Benny Barnhard, Dr. Bettina Bergthold, Dr. J Alexander Bodkin, Dr. Joan Busner, Dr. Osvaldo Caro, Dr. WA de Backer, Dr. Anthony Dietrich, Dr. Bernadette D'Souza, Dr. Luisa Figueira, Dr. Christian Gaussares, Dr. Hermann-Josef Gertz, Dr. Francis Ghysen, Dr. Paul Gross, Dr. Thomas Gualtieri, Dr. Peter Halama, Dr. Ulrich Hegerl, Dr. Fritz Henn, Dr. Ethan Kass, Dr. Arif Khan, Dr. Saaid Khojasteh, Dr. Stephanie Kutler, Dr. Philippe Leclercq, Dr. Pierre Le Goubey, Dr. Robert Levine, Dr. Bruce Lydiard, Dr. Silva Marques, Dr. John Marshall, Dr. Carla Mendez, Dr. K Mulder, Dr. Pascal Pannetier, Dr. Franck Peyre, Dr. Jain Rakesh, Dr. Angelo Samubnaris, Dr. Thomas Shiovitz, Dr. Margot Schmitz, Dr. Martin Schuster, Dr. Georg Schonbeck, Dr. Andreas Strohle, Dr. Marques Teixeira, Dr. Mikel Thomas, Dr. Harry Van Mierilo, Dr. W Veerman, Dr. Hans-Peter Volz, Dr. Jim Whalen and Dr. Marcel ZinsRitter. In addition, we thank Svetlana Dominguez for her editorial assistance and Melissa Spann for her statistical contributions. 


\section{References}

- Acharya, N., Rosen, A.S., Polzer, J.P., D'Souza, D.N., Perahia, D.G., Cavazzoni, P.A., Baldesarini, R.J., 2007. Duloxetine: meta-analyses of suicidal behaviors and ideation in clinical trials for major depressive disorder. J. Clin. Psychopharmacol. 26, 587-594.

- Allgulander, C., Florea, I., Trap Huusom, A.K., 2006. Prevention of relapse in generalized anxiety disorder by escitalopram treatment. Int. J. Neuropsychopharmacol. 9, 495-505.

- Allgulander, C., Hartford, J., Russell, J.M., Raskin, J.R., Erickson, J., Ball, S.G., Rynn, M., 2007. Pharmacotherapy for generalized anxiety disorder: results of duloxetine treatment from a pooled analysis of 3 clinical trials. Curr. Med. Res. Opin. 23, 1245-1252.

- $\quad$ [APA] American Psychiatric Association, 2000. Diagnostic and Statistical Manual of Mental Disorders, 4th edition. American Psychiatric Press, Inc., Washington, DC. Text-Revision.

- Beck, A.T., Kovacs, M., Weissman, A., 1979. Assessment of suicidal ideation: the Scale for Suicidal Ideation. J. Consult. Clin. Psychol. 47, 343-352.

- Boden, J.M., Fergusson, D.M., Horwood, L.J., 2007. Anxiety disorders and suicidal behaviors in adolescence and young adulthood: findings from a longitudinal study. Psychol. Med. 37, 431-440.

- Bruce, S.E., Yonkers, K.A., Otto, M.W., Eisen, J.L., Weisberg, R.B., Pagano, M., Shea, M.T., Keller, M.B., 2005. Influence of psychiatric comorbidity on recovery and recurrence in generalized anxiety disorder, social phobia, and panic disorder: a 12-year prospective study. Am. J. Psychiatry 162, 1179-1187.

- Endicott, J., Nee, J., Harrison, W., Blumenthal, R., 1993. Quality of Life Enjoyment and Satisfaction Questionnaire: a new measure. Psychopharmacol. Bull. 29, 321-326.

- EuroQol Group, 1990. EuroQol: a new facility for the measurement of health-related quality of life. Health Policy 16, 199-208.

- Gelenberg, A.J., Lydiard, R.B., Rudolph, R.L., Aguiar, L., Haskins, J., Thompson, L.E., Salinas, E., 2000. Efficacy of venlafaxine extended-release capsules in nondepressed outpatients with generalized anxiety disorder: a 6-month randomized controlled trial. JAMA 283, 3082-3088.

- Goodman, W.K., 2004. Selecting pharmacotherapy for generalized anxiety disorder. J. Clin. Psychiatry 65 (suppl 13), 8-13.

- Guy, W., 1976a. The clinician global severity and impression scales. ECDEU Assessment Manual for Psychopharmacology [76-338]. US Dept Health, Education, and Welfare, Rockville, MD, pp. 218-222.

- Guy, W., 1976b. The patient's global impression and severity scale. ECDEU Assessment Manual for Psychopharmacology [76-338]. US Dept Health, Education, and Welfare, Rockville, MD.

- Hackett, D., White, C., Salinas, E., 2000. Relapse prevention in patients with generalized anxiety disorder (GAD) by treatment with venlafaxine ER. International Forum on Mood and Anxiety Disorders, Monte Carlo. www.aimgroup.it/2000/ifmad/POSTER20.htm. Accessed 14 April 2008.

- Hamilton, M., 1959. The assessment of anxiety states by rating. Br. J. Med. Psychol. 32, 5055 .

- Hartford, J., Kornstein, S., Liebowitz, M., Pigott, T., Russell, J.M., Detke, M., Walker, D., Ball, S.G., Erickson, J., 2007. Duloxetine as an SNRI treatment for generalized anxiety disorder: results from a placebo and active-controlled trial. Int. Clin. Psychopharmacol. 22, 167-174.

- Keller, M.B., 2002. Raising the expectations of long-term treatment strategies in anxiety disorders. Psychopharmacol. Bull. 36, 166-174.

- Koponen, H., Allgulander, C., Erickson, J., Dunayevich, E., Pritchett, Y., Detke, M.J., Ball, S.G., Russell, J.M., 2007. Efficacy of duloxetine for treatment of generalized anxiety disorder: implications for primary care physicians. Prim. Care Companion J. Clin. Psychiat. 9, 100-107. 
- $\quad$ Leon, A.C., Olfson, M., Portera, L., Farber, L., Sheehan, D.V., 1997. Assessing psychiatric impairment in primary care with the Sheehan Disability Scale. Int. J. Psychiatry Med. 27, $93-$ 105.

- Lipman, R., Covi, L., 1976. Outpatient treatment of neurotic depression: medication and group psychotherapy. Proc. Annu. Meet. Am. Psychopathol. Assoc. 64, 178-218.

- Mahe, V., Balogh, A., 2000. Long-term pharmacological treatment of generalized anxiety disorder. Int. Clin. Psychopharmacol. 15, 99-105.

- McManus, P., Mant, A., Mitchell, P., Dudley, J., 2004. Length of therapy with selective serotonin reuptake inhibitors and tricyclic antidepressants in Australia. Aust. N. Z. J. Psychiatry $38,450-454$.

- Raskin, A., Schulterbrandt, J., Reatig, N., McKeon, J.J., 1969. Replication of factors of psychopathology in interview, ward behaviour and self-report ratings of hospitalized depressives. J. Nerv.Ment. Dis. 148, 87-98.

- Rynn, M., Russell, J.M., Erickson, J., Detke, M.J., Ball, S., Dinkel, J., Rickels, K., Raskin, J.R., 2008. Efficacy and safety of duloxetine in treatment of generalized anxiety disorder: a flexible-dose, progressive-titration, placebo-controlled trial. Depress. Anxiety 25, 182-189 (Electronic publication ahead of print. Feb 20 2007).

- Sareen, J., Cox, B.J., Afifi, T.O., den Graaf, R., Asmundson, G.J.G., ten Have, M., Stein, M.B., 2005. Anxiety disorders and risk for suicidal ideation and suicidal attempts in population-based longitudinal study of adults. Arch. Gen. Psychiatry 62, 1249-1257.

- Shear, M.K., Vander Bilt, J., Rucci, P., Endicott, J., Lydiard, B., Otto, M. W., Pollack, M.H., Chandler, L., Williams, J., Ali, A., Frank, D.M., 2001. Reliability and validity of a structured interview guide for the Hamilton Anxiety Rating Scale (SIGH-A). Depress. Anxiety 13,

- $166-178$.

- Sheehan, D.V., 1983. The Anxiety Disease. Charles Scribner and Sons, New York.

- Sheehan, D.V., Lecrubier, Y., Sheehan, K.H., Amorim, P., Janavs, J., Weiller, E., 1998. The Mini-International Neuropsychiatric Interview (M.I.N.I.): the development and validation of a structured diagnostic psychiatric interview for DSM-IV and ICD-10. J. Clin. Psychiatry 59 (suppl 20), 22-33.

- Sokero, T.P., Melartin, T.K., Rytsälä, H.J., Leskelä, U.S., Lestelä-Mielonen, P.S., Isometsä, E.T., 2003. Suicidal ideation and attempts among psychiatric patients with major depressive

- disorder. J. Clin. Psychiatry 64, 1094-1100.

- Stein, M.B., Cantrell, C.R., Sokol, M.C., Eaddy, M.T., Shah, M.B., 2006. Antidepressant adherence and medical resource use among managed care patients with anxiety disorders. Psychiatric Serv. 57, 673-680.

- Stocchi, F., Nordera, G., Jokinen, R.H., Lepola, U.M., Hewett, K., Bryson, H., Iyengar, M.K., 2003. Efficacy and tolerability of paroxetine for the long-term treatment of generalized anxiety disorder. J. Clin. Psychiatry 64, 250-258.

- Thase, M.E., Than, P.V., Wiltse, C., Pangallo, B.A., Mallinckrodt, C., Detke, M.J., 2005. Cardiovascular profile of duloxetine, a dual reuptake inhibitor of serotonin and norepinephrine. J. Clin. Psychopharmacol. 25, 132-140.

- Wagner, E.H., Austin, B.T., Von Korff, M., 1996. Organizing care for patients with chronic illness. Milbank Q. 74, 511-544.

- Wittchen, H.U., Hoyer, J., 2001. Generalized anxiety disorder: nature and course. J. Clin. Psychiatry 62, 15-19 (discussion 20-21).

- Wittchen, H.U., Jacobi, F., 2005. Size and burden of mental disorders in Europe-a critical review and appraisal of 27 studies. Eur. Neuropsychopharmacol. 15, 357-376.

- WMA, Declaration of Helsinki: ethical principles for medical research involving human subjects.World Medical Association. First adopted in 1964; most recent revision in 2000. Available from http://www.wma.net/e/policy/b3.htm. Last accessed July 17, 2007.

- Yonkers, K.A., Massion, A.O., Warshaw, M.G., Keller, M.B., 1996. Phenomenology and course of generalized anxiety disorder. Br. J. Psychiatry 168, 308-313.

- Zigmond, A.S., Snaith, R.P., 1983. The Hospital Anxiety and Depression Scale. Acta Psychiatr. Scand. 67, 361-370. 